This item was submitted to Loughborough's Research Repository by the author.

Items in Figshare are protected by copyright, with all rights reserved, unless otherwise indicated.

\title{
Systems of systems engineering thesaurus approach: from concept to
} realisation

PLEASE CITE THE PUBLISHED VERSION

http://dx.doi.org/10.1504/IJSSE.2014.065751

PUBLISHER

(C) Inderscience

VERSION

AM (Accepted Manuscript)

LICENCE

CC BY-NC-ND 4.0

\section{REPOSITORY RECORD}

Dogan, Huseyin, Vishal A. Barot, Michael Henshaw, Carys E. Siemieniuch, and Murray A. Sinclair. 2019. "Systems of Systems Engineering Thesaurus Approach: From Concept to Realisation". figshare. https://hdl.handle.net/2134/15168. 
This item was submitted to Loughborough's Institutional Repository (https://dspace.lboro.ac.uk/) by the author and is made available under the following Creative Commons Licence conditions.

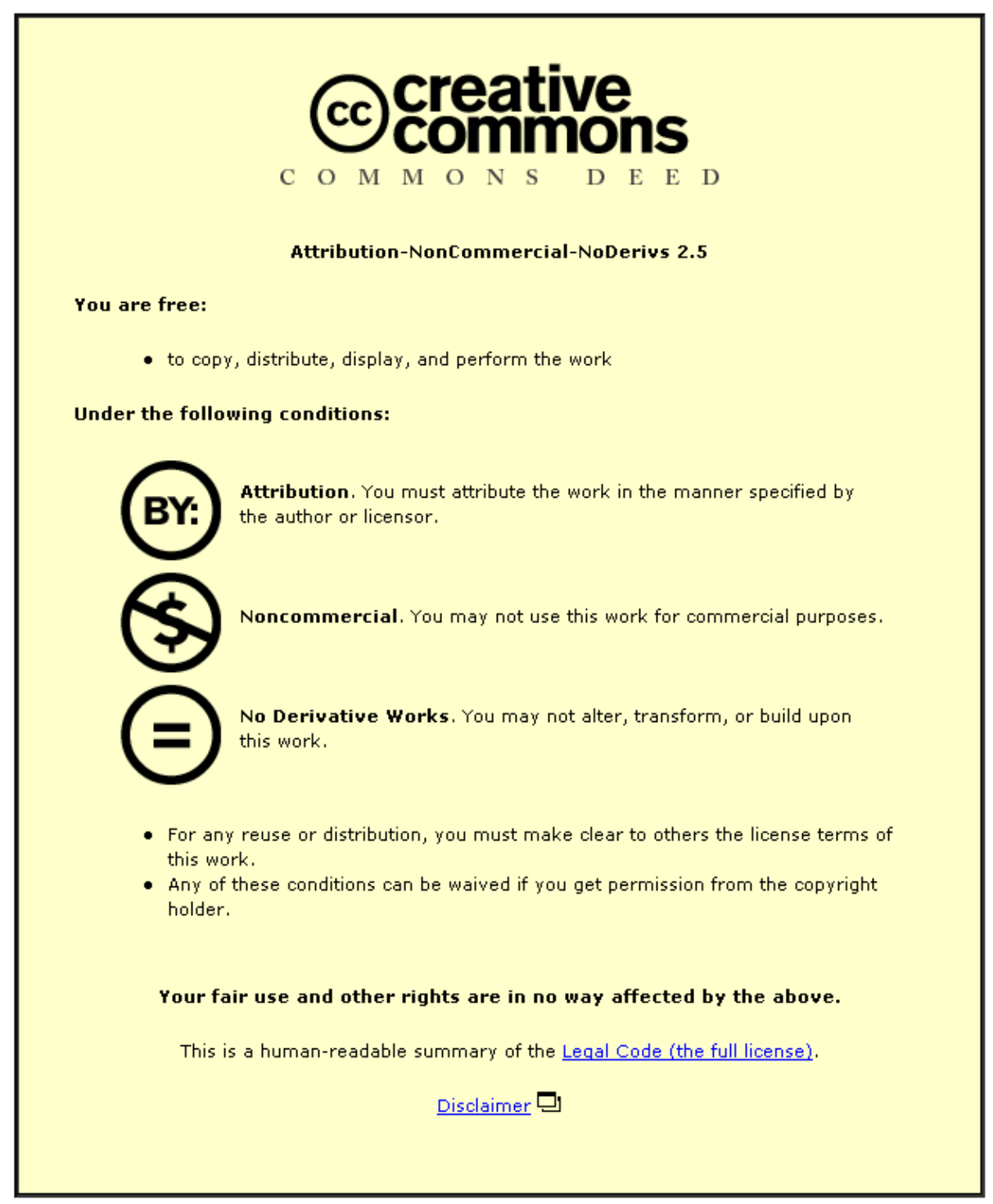

For the full text of this licence, please go to: http://creativecommons.org/licenses/by-nc-nd/2.5/ 


\title{
Systems of Systems Engineering Thesaurus Approach: From Concept to Realisation
}

\author{
Huseyin Dogan* \\ Faculty of Science and Technology \\ Bournemouth University \\ P429, Talbot Campus, Fern Barrow, Poole, Dorset, BH12 5BB, UK \\ Email: hdogan@bournemouth.ac.uk \\ *Corresponding author
}

Vishal Barot, Michael Henshaw, Carys Siemieniuch and Murray Sinclair

Engineering Systems of Systems Group

School of Electronic, Electrical, and Systems Engineering

Garendon Wing, Holywell Park

Loughborough University, LE11 3TU, UK

Email: vish707@gmail.com

Email: m.j.d.henshaw@lboro.ac.uk

Email: c.e.siemieniuch@lboro.ac.uk

Email: m.a.sinclair@lboro.ac.uk

\begin{abstract}
:
The developing discipline of Systems of Systems Engineering (SoSE) is gaining attention in an increasingly broad range of domains; however, each domain comes with its own set of terms and concepts so that there may be confusion between different domains ostensibly engaged in similar challenges. SoSE is faced with concept multiplicity (one term, more than one concept) and term multiplicity (one concept, more than one term). It is unrealistic to expect long-established domains to simply change ontology to match with other domains, but a means of recognising related concepts and terms across domains and across industrial sectors will enable more rapid progress to be made in the development of SoSE. The approach taken to generating a thesaurus, through which such relationships can be documented, is presented. The approach is essentially consultative among SoSE experts and the current version of the thesaurus is available online. A combination of problem statement definition and logical decomposition has been used; the method is described and application is illustrated using well-known terms.
\end{abstract}

Keywords: Thesaurus; Systems of Systems; Terminology; Concepts; Semantic Interoperability; Heterogeneity;

Reference to this paper should be made as follows: Barot, V., Dogan, H., Henshaw, M.J.d., Siemieniuch, C.E. and Sinclair, M. A. (2014) 'Systems of Systems Engineering Thesaurus Approach: From Concept to Realisation’, Int. J. System of Systems Engineering, Vol. 5, No. 2, pp.1-20. 
Biographical notes: Huseyin Dogan is a Lecturer in Systems Engineering and Human Factors and leads the postgraduate programmes in Computing at Bournemouth University. Prior to BU, Dr Dogan worked as a Research Associate within the Engineering Systems of Systems research group at Loughborough University. He has eight years industrial experience working for BAE Systems Advanced Technology Centre, and Military Air and Information.

Vishal Barot was a research project associate at the School of Electronic, Electrical and Systems Engineering at Loughborough University. His main interests and contributions are project management and application of its methodologies, systems engineering industrial research and development, systems architectures and remote data communications. His main expertise is in the areas of project management, systems engineering, systems of systems engineering, and knowledge engineering. Prior to this, Dr Barot worked as a research project associate for numerous industrial researches at Wolfson School of Mechanical and Manufacturing Engineering at Loughborough University for 4 years (2007-11).

Michael Henshaw is Professor of Systems Engineering; he is head of the Systems Division and leads the Engineering Systems of Systems (EsoS) Research Group at Loughborough University. His research focuses on integration and management of complex socio-technical systems, with a particular emphasis on the challenges of through-life management of systems and capabilities.

Carys Siemieniuch is Professor of Enterprise Systems Engineering at Loughborough University. Carys has both UK professional and European CREE registration as an ergonomist, with expertise across the full range of systems-related human factors topics. Her key skills are in knowledge lifecycle management systems, organisational and cultural aspects of enterprise modeling techniques, organisational systems architectures, dynamic allocation of function and the design of complex systems. She is active in both the military and civilian domains.

Murray Sinclair is now a Visiting Fellow at Loughborough University, as well as a Visiting Academic at the University of Sydney. He is a Systems Ergonomist of some 40 years standing, having been an academic member of Loughborough University since 1970. His interests have evolved from the understanding of organisational processes of manufacturing from the shopfloor, through manufacturing systems engineering to design processes and the management of knowledge. Latterly, due to the steady infiltration of information technology into society and its pervasiveness in the lives of individuals, his interests now include the assurance of ethical behaviour by autonomous and semiautonomous systems, such as robots, healthcare systems and the like.

\section{Introduction}

\subsection{Problem Description}

The developing discipline of Systems of Systems Engineering (SoSE) aims to achieve synergy between independently managed and operated heterogeneous systems through effective interoperation and coordination mechanisms (Azarnoosh et al., 2006). SoSE concerns design and management for Systems of Systems (SoS), particularly large-scale complex systems, to obtain an overall desired performance in operation. Traditional 
Systems Engineering approaches require extension for the SoS problem space (Dahmann and Baldwin, 2008; Neaga et. al., 2009), but SoSE is not recognised in some domains and lacks a consistent focus. Owing to the lack of agreement about sufficient SoSE methods, tools and techniques, it is very common to find literature and discussions utilising SE terms and concepts that are discipline specific (Barot et al., 2013a).

SoS communities collect, utilise and disseminate a diverse range of information types (Dogan et al,. 2013) which can lead to confusion among the stakeholders involved in specific SoS, especially when relevant terminologies are miscommunicated within and across all the levels of a SoS hierarchy. The lack of linguistic clarity occurs at a cost to the SoS discipline, as well as the communicators within specific SoS (Barot et al., 2013a). The need for consistent representation, interpretation and sharing of SoS terminologies is essential in the current globalised, competitive and innovative environment. Moreover, as the popularity and exposure to SoS and SoSE concepts expands into a wider range of domains, more heterogeneous models, and tools and techniques are being developed for SoS operations, management and its governance (COMPASS, 2012; DANSE, 2012). Semantic clarity among SoS practitioners is therefore essential to align these models, tools and techniques.

Tolk et al. (2011) embedded the idea of ontology for semantics into the improved use of intelligent agents, modelling and simulation to define the foundation to communicate SoSE challenges. Keating and Katina (2011) developed a perspective of the state of the SoSE field and implemented an organising framework to structure SoSE. They also suggested advancement of the SoSE field by offering an emerging set of common systems-based pathologies (e.g. constraining performance and sustaining existence) that may be prevalent in SoS (Keating and Katina 2012). Similar research developments date back to the previous decade. For example, Keating (2005) introduced a contemporary perspective of SoSE and identified a preliminary set of critical topical research areas for development of a more integrated research agenda for SoSE. This consisted of a framework of five logical levels (philosophic, axiomatic, methodological, application, and method) to provide a level of organisation to ensure more robust consideration of SoSE research undertaken. Furthermore, Henrie and Delaney (2005) extended the definition of common terms used in traditional systems engineering to SoS research. SOSE descriptions for concepts such as complexity, domain, bounding and environment were described with examples. Valerdi et al. (2007) provided a framework for examining the differences between systems engineering and SoSE though the categorisation of concepts into normative, descriptive, and prescriptive models. A report on SoSE by SIT (2006) stated that the distinction of SoS comes from the manner in which parts and relationships are gathered together and therefore in the nature of the emergent whole. This entails issues such as constituent systems forming their own connection and variety in their diversity exhibiting challenges to communication. The current research is a continuation of the prior research initiatives mentioned above to break the barriers that inhibit communication of SoSE concepts across different communities.

To address the aforementioned challenges, a SoSE thesaurus has been created as part of a European Commission funded support action called T-AREA-SoS ${ }^{1}$. This thesaurus underpinned the development of a SoSE research agenda, and it aims to ensure that SoS terminologies (concepts and terms) are consistently interpreted; it should provide an

\footnotetext{
${ }^{1}$ Trans-Atlantic Research and Education Agenda on Systems of Systems: www.tareasos.eu
} 
artefact that will be of assistance to planners of future programmes in SoSE and large scale complex systems. A thesaurus groups words of similar meaning; as such this thesaurus should be a useful resource for research activities within SoSE, by relating definitive terms from different domains for proposers and researchers, thus adding to the clarity of SoS-related outputs. The thesaurus will support the development of theoretical foundations in SoSE that will aid the drive towards agreed principles for development and operation of SoS. Although the concept of SoS has only been discussed using SoS language for a couple of decades, it is obvious that SoS problems have existed for much longer. For this reason, a thesaurus approach has been chosen, rather than a lexicon approach. The purpose is to aid communication across sectors and domains, and to make practitioners aware of language differences, not to attempt to formalise a SoSE ontology. This approach is regarded as practical for making progress in real-world applications.

This paper is about the application of known methods in SoS which leads to new insights or capabilities; it is organised in five sections. The problem space is contextualised and a brief background about the origins of this research is provided in this first section. A review of methods, tools and techniques for development of thesauri is provided in the second section. An overview of the applied methodology is provided in the third section and the realisation of the SoSE thesaurus with example illustrations are given in the fourth section. The final section comprises conclusions and future work, discussing the overall contribution of this paper and how it will influence decision making and day-today communications within various sections of the SoS community.

\subsection{Preamble}

According to "ISO 25964 - Part 1: Thesauri for information retrieval" (ISO, 2011), a thesaurus is a standardised representation of language, designed to clarify the definition and structuring of key terms and associated concepts in a specific discipline. In order to ensure its wide acceptance and usability within the SoS communities, it is important that this thesaurus be collectively populated by a distributed group of experts and peerreviewed (in this case by an expert community established within the T-AREA-SoS project). It is anticipated that this expert community will use the thesaurus as a logical place to record and refer to SoS concepts which are common to all objects to which a term might be applied and vice versa.

The expert community for T-AREA-SoS included expertise from nearly forty different industrial sectors but, nevertheless, is self-selecting in terms of people being SoS-aware. A challenge is to be able to adequately engage communities for which SoS does not form part of their regular lexicon.

A concept is an idea or mental image which corresponds to some distinct entity or class of entities, or to its essential features, or determines the application of a term (especially a predicate) and thus plays a part in the use of reason or language. On the other hand, a term is a word or phrase used to describe a thing or to express a concept, especially in a particular kind of language, work context or branch of study (Barot et al., 2012), This implies that a term is an actual word whereas a concept is the meaning of a word that may require a model, or textual description or crafted definition in order to be conveyed. 


\subsection{Conceptual Study}

This research project consisted of several phases. An initial conceptual study was carried out to better understand how numerous terms and concepts were communicated within and across various domains. The sources of information gathered were from an extensive state of the art review of SoS (Barot et al., 2013b), a gap analysis conducted to determine priority research areas in SoSE (Henshaw et al., 2012a), and a series of International expert workshops, conference panel sessions, and workshops between various EU FP7 projects concerning SoS. The conceptual study was conducted with two goals in mind. First, to identify problems that people face when they communicate and discuss commonly used SoS concepts and terms in their respective domains. Secondly, to identify realistic cases where lack of linguist clarity is problematic. From these activities, two specific challenges emerged:

- Concept multiplicity: There may be a specific term used by various communities and in different contexts. Each community may be using this same term but to describe slightly different concepts, therefore application of each term within its specified context may mean different things with different connotations to different communities. This implies that one term may express more than one concept.

- Term multiplicity: A SoS concept may be labelled by different terms in different communities. This implies that one concept may be recognised using more than one term.

The authors' intention was to understand where and how a thesaurus-based approach could be used to guide the presentation of specific SoSE terminology across different industrial sectors. It is evident that, for engineering, management and communication purposes across a wide range of stakeholder disciplines, there is a need for consistency in the usage of terms and concepts. This matter is illustrated in Figure 1.

Figure 1 assumes that stakeholders are concerned with a real-world matter requiring their attention. This matter will be conceptualised by the various stakeholders in terms relevant to their own communities. Since some level of communication will be required between these stakeholders, an interpretation may be required. This is the function of the SoSE thesaurus, represented by the rectangular box in Figure 1. Furthermore, the thesaurus may be used to crystallise the meaning of the concepts among the stakeholders within a community. Also, the real-world issue may necessitate new or re-defined concepts or terms. If new concepts are introduced by one community then these must be incorporated into established ontologies. This will also be important to support development of modelling and simulation of SoS and interpretation of results by multiple communities. 


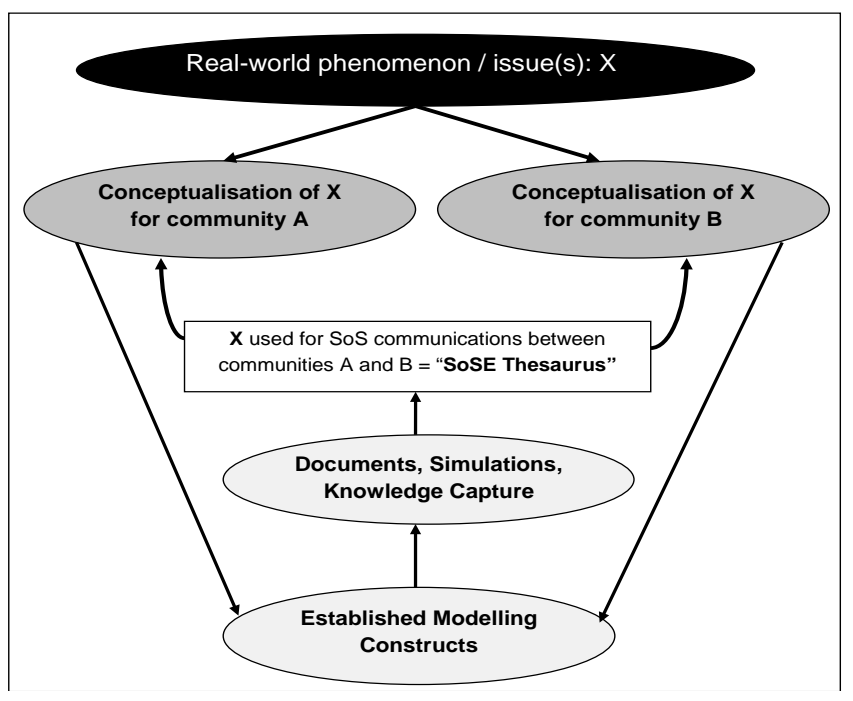

Figure 1: Illustration of the Role of the SoSE Thesaurus

\section{Review of Methods, Tools and Techniques for SoSE Thesaurus Realisation}

From the conceptual study it was evident that there was a need to formalise definitions of concepts and terms, and map these terminologies between various domains. This required the authors to review various methods, tools and techniques that could be used to express relationships between terms and concepts to construct thesaurus terminologies in a collaborative context. The objective of this section is to explore some of the options available, with the goal of identifying those most appropriate for use for realisation of the SoSE thesaurus.

\subsection{Problem Statement Approach}

Newman and Lamming (1995) describe a problem statement approach where a definition of design objectives brings together the components of the design problem. At the very outset one can usually find a short phrase to describe some components of the design statement and incorporate them into a single sentence. This sentence becomes a structural template with components as placeholders or slots which can be populated using a series of stages as the design matures. Figure 2a illustrates the basic template structure of a problem statement as described by Newman and Lamming (1995). Figure $2 b$ illustrates how this template statement can be reused as required through examples. 
Systems of Systems Engineering Thesaurus Approach: From Concept to Realisation

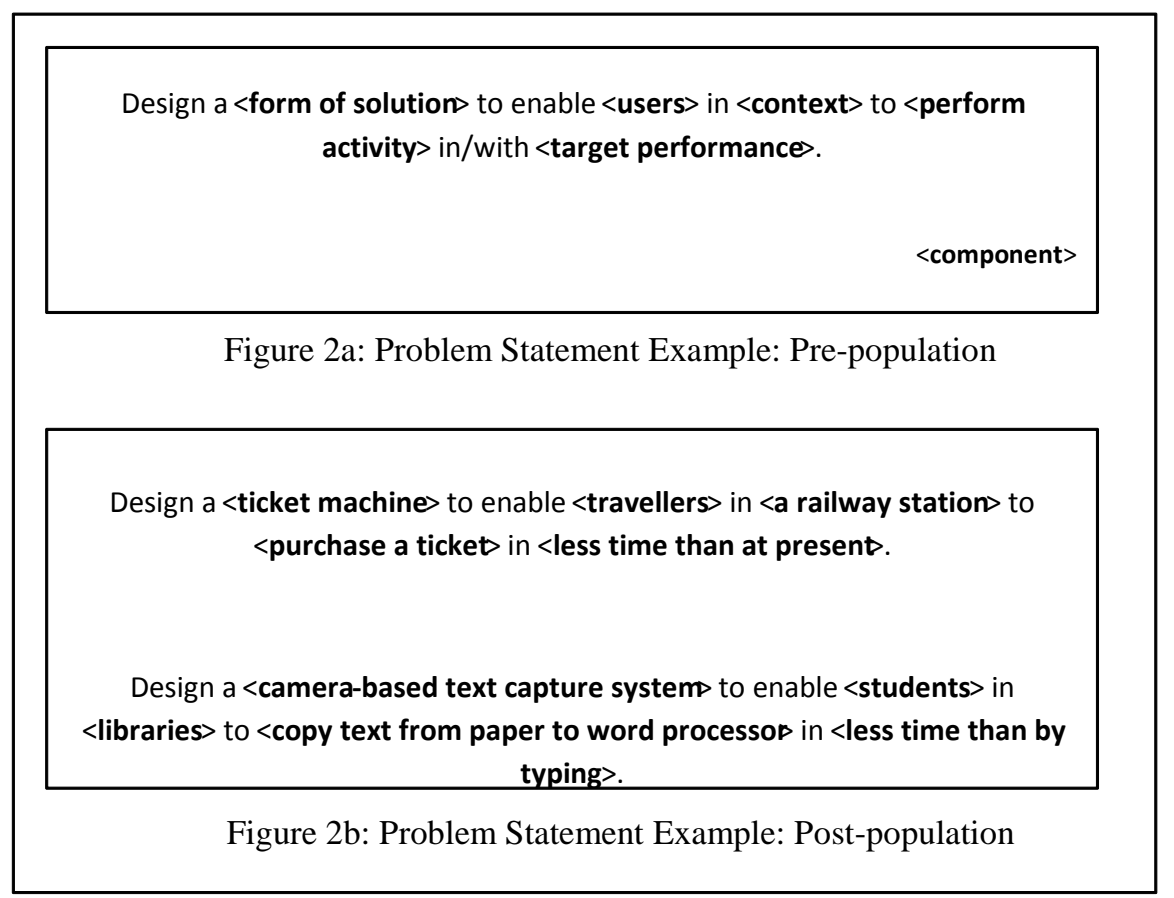

Figure 2 shows that constructing a problem statement through stage-based slot population enables system design issues to be communicated with a clear understanding as and when the information becomes available (Newman and Lamming, 1995). Similarly, this approach can be utilised when constructing a thesaurus statement i.e. it starts with some aspects of the problem in place and works towards filling in the rest of the component details.

\subsection{Thesaurus Editors}

Thesaurus editors, which are most appropriate for knowledge organisation systems (Catapano et al., 2011), support the acquisition and organisation of both terms and their associated concepts. Corresponding tools rely on standards such as the thesaurus norms ISO 2788 and BS 8723 (ANSI, 2005) and the W3C SKOS ${ }^{1}$ standard (Isaac et al., 2009), which provides guidance for the representation of the thesaurus terminologies and facilitate their diffusion, exchange and sharing. For example, SKOEd editor (Jupp et al., 2009) is based on the SKOS standard recommended by the W3C to represent thesaurus terminologies, and the TemaTres editor (http://www.vocabularyserver.com/) allows users to choose the data format from e.g. SKOS, Zthes or BS8723 among others. A major advantage of SKOS is that the knowledge systems in the process of being acquired are kept fully compatible with the standards of the semantic web, enabling both their diffusion and interoperability.

\footnotetext{
${ }^{1}$ Simple Knowledge Organisational System
} 
While many thesaurus terminologies have been constructed using the SKOS format in the life and environmental sciences sector such as GEMET ${ }^{1}$ and AGROVOC ${ }^{2}$ (Soergel et al., 2004), no attempt has been made to construct one within SoSE (or even SE) context. Since thesaurus editors should be simple to use for the generation, maintenance and consultation of thesaurus terminologies, they usually come with user-friendly interfaces. A drawback is that they are usually tightly associated with the underlying representation standards, which strongly influence the model that structures the terms and associated concepts. These different editing environments allow an efficient, easy and even sometimes semi-automated thesaurus construction, but they seldom offer mechanisms that take the collaborative aspects of terminology construction into account.

\subsection{Collaborative Tagging Systems}

Collaborative labelling systems (such as Flickr, BibSonomy (Hotho et al., 2006)) enable internet users to exchange their perceptions and points of view through the addition of freely defined labels or tags, thereby enriching and describing any available web resource (e.g. image, text, video, audio, etc). These systems lead to the identification of three areas of interest: the described web resources, the users and their main interests and the newly created labels. The added information can be used to expand the access and consultation conditions to this resource. Tags can lead to new forms of organisations called "folksonomies" (Hotho et al., 2006), which reflect the creativity and sensitivity of experts. Tags can therefore be considered as the starting points of a bottom-up approach to the construction of new data repositories (data and/or documents). In turn, these can be used as innovative tools and techniques with browsing functionalities in closer adequacy with an expert's sensitivity.

A major drawback is the great freedom with which users can define their tags. Indeed, a tag can be considered as a piece of metadata, or data on data, and can be manipulated as a property-value couple. Each property has declared semantics and each associated value reveals the information content of the metadata. Applying metadata to a web resource enriches it with additional information, but also simplifies its potential exploitation by software agents. It is then possible for any Internet user to complete either the value of the tag, or in the best case, the value of the tag and the property of the association relating this value to the tagged resource. A main issue is that this can be done without concerted action by other users. The organisational task of these tags is therefore restricted to the construction of very simple classifying systems such as that of folksonomies. Such a widely open approach favouring a weakly constrained participation of users cannot be implemented to collectively construct thesaurus terminologies, which requires a high degree of agreement among experts.

\subsection{Semantic Wikis}

With semantic wikis, the objective is to provide web users (in this case, SoS experts) with collective working spaces to co-construct resources, most often documents. Wiki-type web sites can be proposed to a very wide public (Wikipedia at http://www.wikipedia.org/) or to a narrower and more focused community. In both cases, the aims of the wiki are on the one hand to share content to reach consensus or at least a certain degree of agreement, and on the other hand to keep the history related to the coconstruction. These wikis can be considered as "semantic wikis", since they actually

\footnotetext{
${ }^{1}$ General Multilingual Environmental Thesaurus

2 Thesaurus of Food and Agriculture Organisation of the United Nations
} 
integrate knowledge representation layers coming from web semantic technologies. They can be used in two complementary ways. First, experts can consolidate the wiki content based on their particular knowledge, to improve the access, sharing and reasoning on this content. Second, a knowledge scheme can be derived from the collectively improved wiki content, with the objective to identify concepts and relationships between these concepts. The limits of these systems pertain to the way the history of changes is handled, the controls on the origins of the information and the mechanisms developed to insure consensus. This brings concerns about the level of confidence that can be granted to a collective knowledge scheme designed openly without any formal supervision of the activities that have led to its elaboration.

\subsection{Logical Decomposition Modelling}

The logical decomposition modelling technique (Dickerson and Mavris, 2009) can be used to reason about and assess definitions to explore the relationship between concepts, principles and terminology. The objective of this technique is to "extract the relations that comprise the defined term by using a modelling language to derive a minimal model of relations (i.e. one that adds no new meaning) but that is complete and captures the intended meaning of the term (i.e. all intended relations have been captured") (Dickerson, 2008).

This technique involves listing all the key words that will be undefined and using a notation from UML (Unified Modelling Language) or SysML (Systems Modelling Language) to determine the relationships, and hence the meaning, of terms. The natural language notation of this approach is summarised as follows (Dickerson and Mavris, 2009):

- Each word in the definition is italicised except for the defined term.

- The defined term is capitalised with: bold font, not italics.

- The key words in the definition use: bold font, not underlined.

- Other words in the definition use: bold font, not italics

- Additional words (not in the definition) use: not bold, not italics.

- Graphical notation includes nouns which are placed in boxes; verbs and relations are placed on lines; solid boxes and lines are used for key words and other words from definition; and dash-dot graphics are used otherwise.

To demonstrate an example, a logical decomposition model "Systems of Systems" is shown in Figure 3, based on the definition of Jamshidi (2009). As shown in the figure, a set of key terms can be extracted from the definition of a "System of Systems"; these are: integration, constituent systems, certain higher goal(s), networked together, independent, operable, and period of time. Similarly, any thesaurus statement can be decomposed using this technique to formalise the relationships between SoSE terms and concepts, modelling the intended meaning of these terminologies. 
A System of Systems is an integration of a finite number of constituent systems which are independent and operable, and which are networked together for a period of time to achieve a certain higher goal(s)

(Jamshidi, 2009)

\section{A SYSTEM OF SYSTEMS is an integration of a finite number of constituent systems which are independent and operable, and which are networked together for a period of time to achieve a certain higher goal(s)}

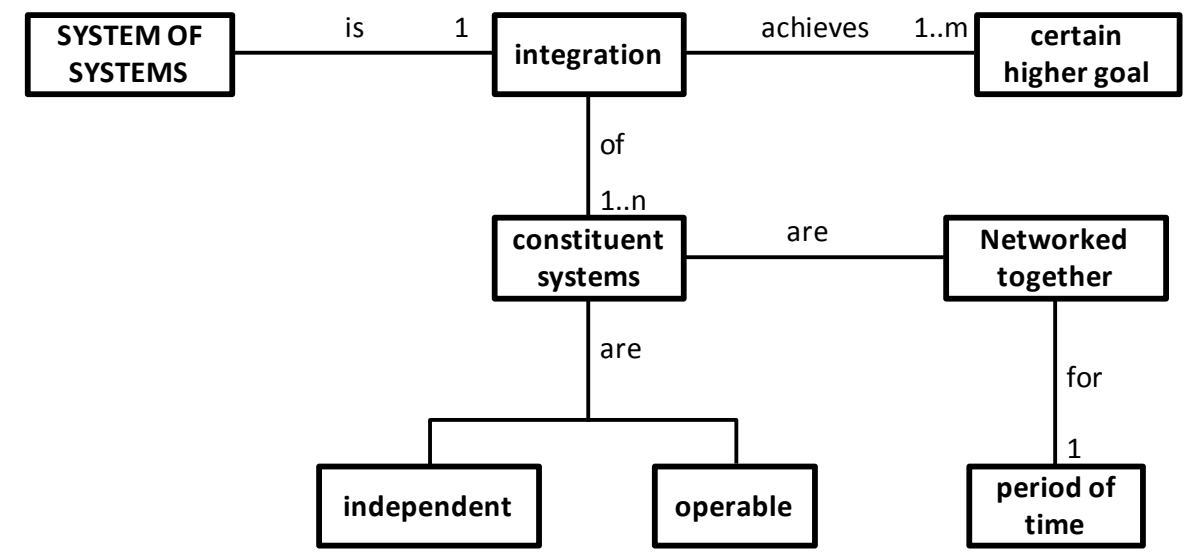

Figure 3: Simplified Representation of Logical Decomposition Model for a System of Systems

\subsection{Traditional Approaches and Ontology Editors}

Other traditional approaches that can support the formalization and mapping of the terminologies for the SoSE thesaurus include Entity Relationship Diagrams (ERDs), class diagrams of UML, Integration Definition (IDEF), document analysis and linguistic analysis, to name but a few. However, these approaches do not involve a series of steps as identified in the problem statement approach and logical decomposition modelling techniques for identification and structuring of the thesaurus terminologies. Ontologybased modelling has been widely used for defining concepts (Hughes et al., 2009; Duan et al., 2009; Liu et al., 2010). An ontology-based approach is complementary to more conventional modelling approaches such as UML and SysML because ontology is intrinsically tied to the definition of a domain i.e. "what is", as in "what is SoSE and how is it different from other engineering domains?" The classes and relationships typically associated with the model can also be added. Languages such as Web Ontology Language (OWL) and Integrated Definition for Ontology Description Capture Method (IDEF-5) and tools like Protégé and Hozo are applicable for ontology development.

The construction of ontologies has recently benefited from the implementation of tools based on semantic web standards, allowing people to work collectively. The 
Collaborative Protégé tool (Tudorache et al., 2008), a plugin of the Protégé environment devoted to the construction of ontologies (Gennari et al., 2003), offers functionalities adapted to community approaches. Collaborative Protégé is available either as a single or multi-user product and manages the history of all editing and annotation activities pertaining to the entities defined in an ontology. All these activities are organized using the ChAO ontology (Change and Annotation Ontology: Noy et al., 2006). This additional structure level is of considerable help for management and control during the construction and evolution of the considered ontologies. However, the use of Collaborative Protégé and Protégé has proven too complex for most experts in various fields, who have neither been trained in the basics of ontology construction nor in the Protégé environment (Schober, 2009). More generally, a recent survey shows that over $50 \%$ of survey participants felt they had insufficient technical support to develop ontologies, while more than $30 \%$ consider that existing tools were unfriendly (Catapano et al., 2011). Furthermore, constructing an ontology for SoSE using a thesaurus will have representational problems with respect to such emerging web standards for knowledge representations. Existing research that focuses on transitioning from a thesaurus to an ontology (Wielinga et al., 2001) can guide the development of a future SoSE ontology that can be derived from the proposed SoSE thesaurus approach in this article.

\section{The Methodology Applied for Thesaurus}

\subsection{Synthesis}

The overall objective is to have a thesaurus which enables terminology construction within a collaborative context (i.e. a community of experts). The approach should be simple, user-friendly and be easily implemented on the web. Each SoS expert must be able to create, edit and comment on the terms and concept entries, and validate or reject the proposals of the other experts. Particular attention must be given to the history of the different activities carried out by the experts and to the various versions of the thesaurus over time. This is necessary if one wants to retain control over the thesaurus and assess its quality throughout its lifespan. The review of the various approaches in the section 2 has revealed the limits and opportunities of the currently available methods, tools and techniques, and identification of the features that enable re-use functionality within the SoSE thesaurus.

\subsection{Implemented Approach}

A combination of problem statement definition approach (Newman and Lamming, 1995) and logical decomposition models (Dickerson and Mavris, 2009), as discussed in section 2, has been used to formalise definitions of concepts and terms, and to map between various domains such as defence, ICT, manufacturing, energy and transport. The thesaurus can be used for two distinct purposes as illustrated by the logical models and examples below (Dogan et al., 2013).

\section{Purpose 1: One Term, More Than One Concept (Concept Multiplicity)}

A one-sentence thesaurus statement for the concept multiplicity problem can be constructed considering the following elements:

- a term to express at least one concept;

- a concept defined through logical decomposition; 
- a community from which the concept originates;

- a context in which the concept is used.

The corresponding logical decomposition model for concept multiplicity is shown in Figure 4:

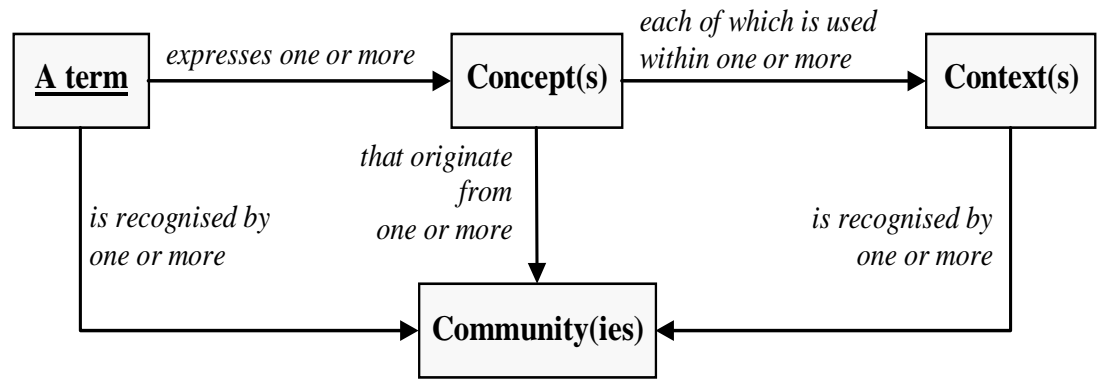

Figure 4: Logical Model Structure for the Purpose 1 - Concept Multiplicity

Figure 4 illustrates that a term may express one or more concept(s) that originate from one or more community(ies) and is used within one or more context(s). A term is also recognised by one or more community(ies).

\section{Purpose 2: One Concept, More Than One Term (Term Multiplicity)}

A one-sentence thesaurus statement for the term multiplicity problem can be constructed considering the following elements:

- a concept defined through logical decomposition to identify at least one term;

- a community where the term is recognised; and

- a term identified by one community may not be recognised by another community.

The corresponding logical decomposition model for term multiplicity is shown in Figure 5: 


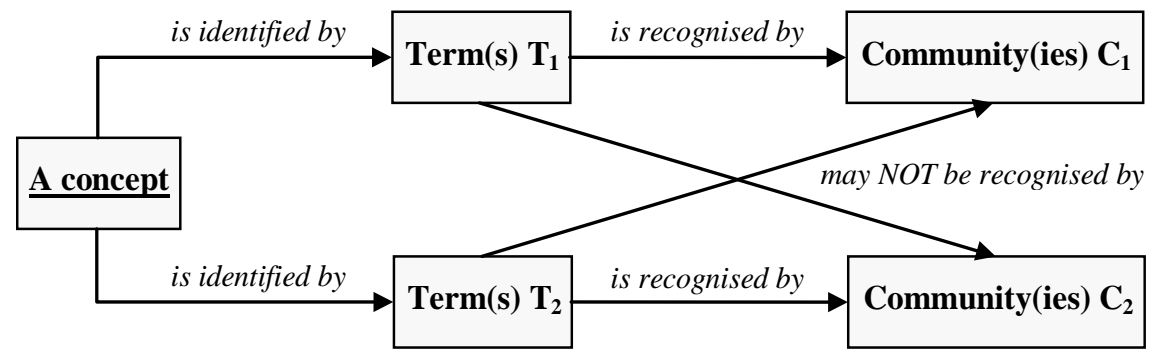

Figure 5: Logical Model Structure for the Purpose 2 - Term Multiplicity

Figure 5 illustrates that a concept is identified by a specific term used by one or more community(ies). The same concept may be identified by different community(ies) using different terms. The term used to identify a concept by one community may not be recognised by another community. The resulting thesaurus statements generated through application of one-sentence problem statement approach can provide the following template structures:

\section{Purpose 1: Concept Multiplicity (template structure)}

A $<$ term $>$ expresses one or more $<$ concept(s) $>$ that originates from one or more $<$ community(ies) $>$ and used within one or more $<\operatorname{context(s)}>$. The $<$ term $>$ is also recognised by one or more $<$ community(ies) $>$.

Purpose 2: Term Multiplicity (template structure)

A $<$ concept $>$ is identified by a $<$ term $>$ used by one or more $<$ community(ies) $>$. The $<$ concept $>$ may be identified in different $<$ community(ies) $>$ using different $<$ terms $>$. The $<$ term $>$ used to identify a $<$ concept $>$ by one $<$ community $>$ may not be recognised by another <community>.

The placeholders in the above template structures $(<>)$ are populated by the SoS community of experts, and the corresponding logical models are generated. Collectively these provide guidance through consistent representation of commonly used terminologies from SoSE across various domains.

\section{Realisation}

\subsection{Application Illustration}

To illustrate the applicability of the thesaurus approach, an example for each purpose (purpose 1 and purpose 2) is described in this section. The examples drawn are from the T-AREA-SoS state of the art report (Barot et al., 2013b) and the literature reported therein.

Example 1: Concept Multiplicity. In this example, a term namely "Enterprise Architecture" is used to express multiple meanings. The general meaning of this term is: 
An Enterprise Architecture (EA) is architecture of an organisation that supports strategy, analysis, and planning by stakeholders to determine how the organisation can most effectively achieve its current and future (Barot et al., 2013b). However, the same term is interpreted in four different ways as described by Ross et al. (2006), depending on the community and its context as shown in the Table 1:

Table 1: An Example of Concept Multiplicity

\begin{tabular}{|c|c|c|}
\hline \multicolumn{3}{|c|}{ Term: Enterprise Architecture } \\
\hline Concept (Definition) & Community & Context \\
\hline $\begin{array}{l}\text { Business process architecture: } \\
\text { the activities or tasks } \\
\text { composing major business } \\
\text { processes identified by the } \\
\text { process owners. }\end{array}$ & $\begin{array}{l}\text { - Business Management. } \\
\text { - Process Engineering. }\end{array}$ & $\begin{array}{ll}\text { - } & \text { Business Process } \\
& \text { Modelling. E.g. IDEF0. }\end{array}$ \\
\hline $\begin{array}{l}\text { Data or information } \\
\text { architecture: shared data } \\
\text { definitions. }\end{array}$ & $\begin{array}{l}\text { - Database Managers. } \\
\text { - Information } \\
\text { Architects. } \\
\end{array}$ & $\begin{array}{l}\text { - Semantic Web and } \\
\text { Databases. E.g. XML. }\end{array}$ \\
\hline $\begin{array}{l}\text { Applications architecture: } \\
\text { individual applications and } \\
\text { their interfaces. }\end{array}$ & $\begin{array}{l}\text { - Software Developers. } \\
\text { - Solution Architects. }\end{array}$ & $\begin{array}{l}\text { - Software Platforms. E.g. } \\
\text { operating systems. }\end{array}$ \\
\hline $\begin{array}{l}\text { Technology architecture: } \\
\text { infrastructure services and } \\
\text { technology standards they are } \\
\text { built on. }\end{array}$ & $\begin{array}{ll}\text { - } & \text { Technology } \\
\text { Management. } \\
\text { - Service Management. }\end{array}$ & $\begin{array}{l}\text { - Technology and Service } \\
\text { Infrastructure E.g. an } \\
\text { airport. }\end{array}$ \\
\hline
\end{tabular}

For example, the business process architecture (concept \#1 in Table 1) can be populated in the format of the thesaurus template statement as illustrated below:

A term <Enterprise Architecture $>$ expresses the concept of <Business process architecture: the activities or tasks composing major business processes identified by the business process owners $>$ and originates from the communities of $<$ Business Management $>$ and used within the context of a $<$ Business Process Modelling $>$. The $<$ Enterprise Architecture $>$ is also recognised by communities of $<$ Process Engineering $>$.

The corresponding logical model for "Enterprise Architecture" for concept \#1 is illustrated Figure 6.

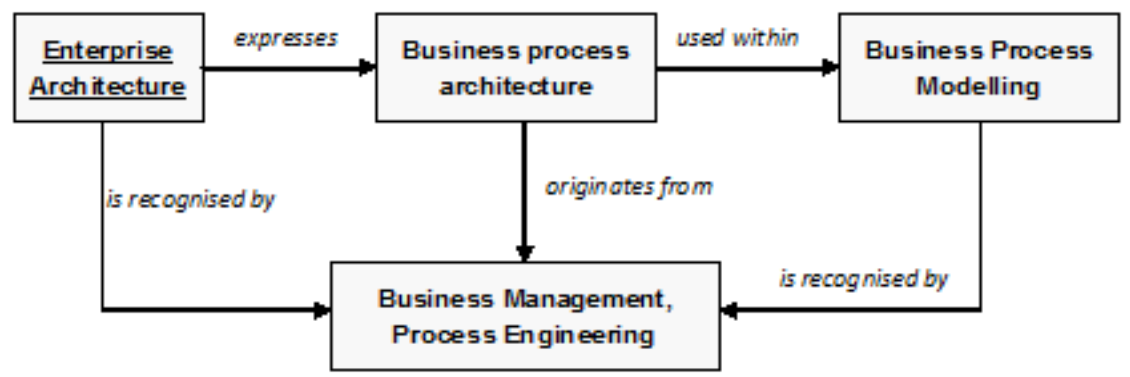

Figure 6: Logical Model Representation for Enterprise Architecture (as defined by Concept \#1 of Table 1) 
Example 2: Term Multiplicity. In this example, a concept namely "System of Systems" (as recognised by the IEEE and INCOSE Systems Engineering communities) is labelled by multiple terms as shown in the Table 2 below:

Table 2. An Example of Term Multiplicity

\begin{tabular}{|c|c|c|c|}
\hline \multicolumn{4}{|c|}{$\begin{array}{c}\text { Concept Definition: SoS is an integration of a finite number of constituent systems } \\
\text { which are independent and operable, and which are networked together for a period of } \\
\text { time to achieve a certain higher goal (Jamshidi, 2009). }\end{array}$} \\
\hline Term & Community & Context & Synonym \\
\hline $\begin{array}{l}\text { Systems of } \\
\text { Systems } \\
\text { (Jamshidi, 2009) }\end{array}$ & $\begin{array}{l}\text { Systems Engineering } \\
\text { including INCOSE and } \\
\text { IEEE Systems Council. }\end{array}$ & $\begin{array}{l}\text { Generic perspective and can be } \\
\text { applied to various domains such } \\
\text { as manufacturing, energy, etc. }\end{array}$ & $\begin{array}{l}\text { Family of } \\
\text { Systems }\end{array}$ \\
\hline $\begin{array}{l}\text { Whole Systems } \\
\text { (Elphick, 2011) }\end{array}$ & $\begin{array}{l}\text { Transport } \\
\text { rail comm } \\
\text { UK }\end{array}$ & $\begin{array}{l}\text { noney and } \\
\text { ch as Crossrail }\end{array}$ & N/A \\
\hline $\begin{array}{l}\text { Family of } \\
\text { Systems } \\
\text { (Dickerson \& } \\
\text { Mavris, 2009) }\end{array}$ & $\begin{array}{l}\text { Department of Defense } \\
\text { and Systems } \\
\text { Engineering }\end{array}$ & $\begin{array}{l}\text { Generic perspective and can be } \\
\text { applied to various domains such } \\
\text { as manufacturing, energy, etc. }\end{array}$ & $\begin{array}{l}\text { Systems of } \\
\text { Systems }\end{array}$ \\
\hline
\end{tabular}

The example shown in the Table 2 can be populated using the format of the thesaurus statement as shown below:

A concept of <integration of a finite number of constituent systems which are independent and operable, and which are networked together for a period of time to achieve a certain higher goal $>$ is identified as $<$ Systems of Systems $>$ recognised by communities of $<$ Systems Engineering including INCOSE and IEEE Systems Council $>$. This concept is also identified by communities of < Transport especially the rail community in the UK> using the term <Whole Systems>, and communities of $<$ Department of Defence and Systems Engineering $>$ using the term $<$ Family of Systems $>$. The term $<$ Systems of Systems, Family of Systems $>$ are synonyms whereas the term $<$ Whole Systems $>$ does not recognise other terms for this concept within its community.

The community associations for the Systems of Systems / Whole Systems / Family of Systems are illustrated in Figure 7. 


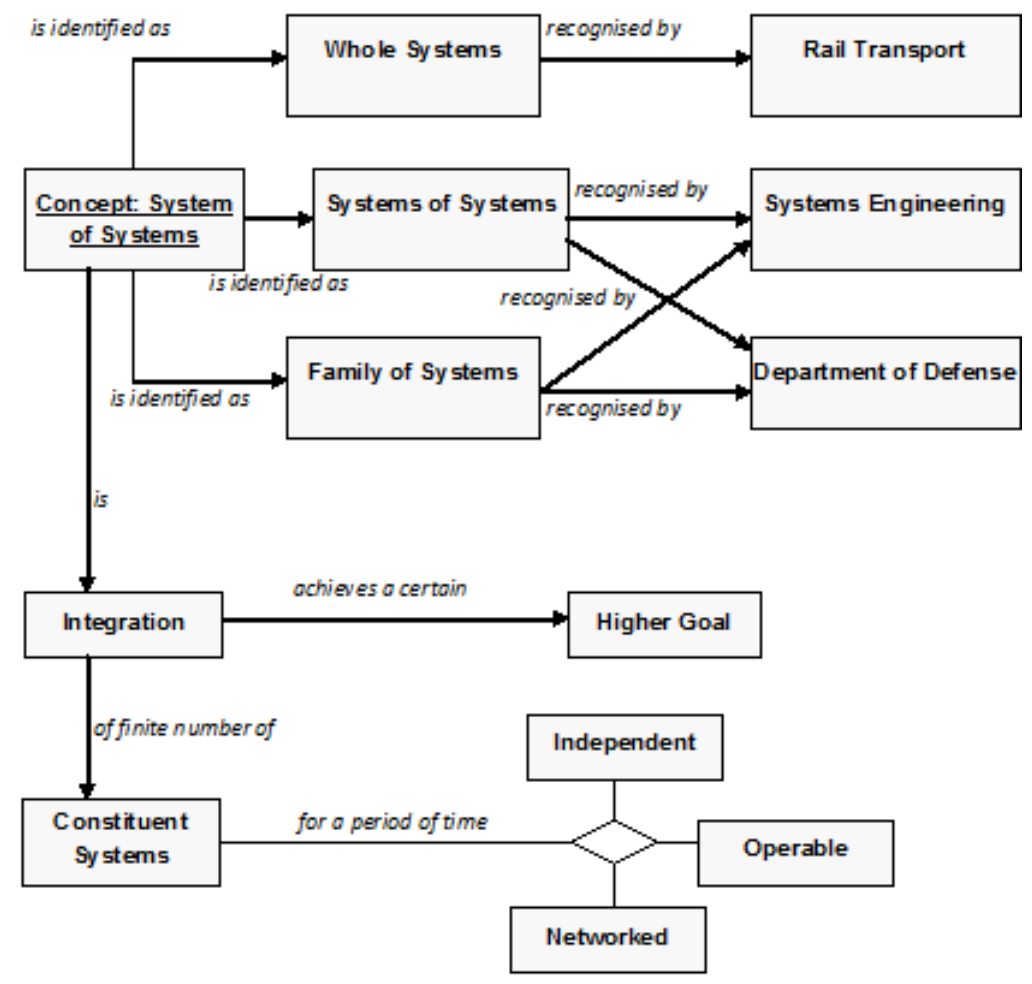

Figure 7: Logical Model Representation for System of Systems Concept

A report that forms Version 3.0 of the SoSE thesaurus (T-AREA-SoS, 2013a) was generated through contributions made by the T-AREA-SoS expert community. The concept definitions of terms such as agility, design, interoperability, performance measurement, governance, resilience, sustainment, networks, evolution, integration, emergence and value were generated. For example, the term "resilience" as used in Mechanical Engineering will differ from the Systems Engineering community. Similarly, the term "integration" in the Social Sciences community refers to the movement of minority groups whereas in Mathematics the term integration is a fundamental concept of calculus. In broader terms in Systems Engineering the term integration involves integrating existing often disparate systems (T-AREA-SoS, 2013a).

It is important that the thesaurus does not simply duplicate existing resources, but rather builds on works in which standard definitions exist, supplements these with alternatives where such alternatives are consistently used by one or more communities, and is selective to ensure that only those terms and concepts of particular relevance to SoS are included. The following sources were considered at the outset, to provide terms and concepts of relevance. Even within these, some of the differences noted above are apparent.

- BKCASE (Body of Knowledge and Curriculum to Advance Systems Engineering) 
- ISO / IEC standards for Systems and Software Engineering such as:

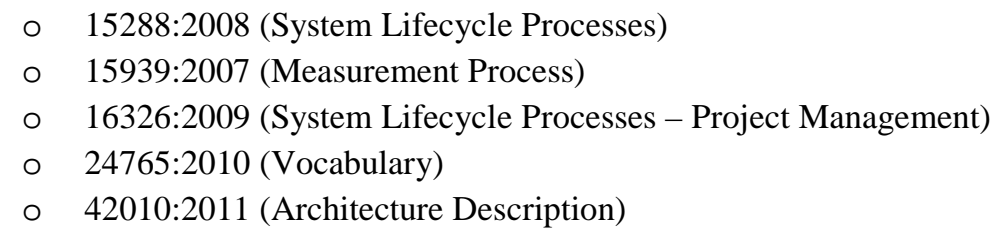

Initial selection of entries for the thesaurus was decided partly by expert opinion and also through frequency of use in SoS relevant documents.

This approach is designed to clarify the definition and structuring of key terms and associated concepts in a specific discipline. The terms and concepts are set in advance where the associated context and communities are identified. This does not involve any synthesis of terms and/concepts to come up with our own definition, it is more about the use of terms in different disciplines. The validation of the thesaurus approach involved releasing a summary of the approach to the T-AREA-SoS expert community to obtain feedback and derive applicable use cases. A set of terms and concepts were introduced to the expert community to develop the initial set for the SoSE thesaurus. This validation can also be supported by a web-based moderation activity as discussed in the next section.

\section{Future Work, Discussions and Conclusion}

\subsection{Potential web-based development}

A web-based template as illustrated in Figure 7 can be developed and provided to the SoS expert community (established as part of the T-AREA-SoS project) for populating a webbased thesaurus system.

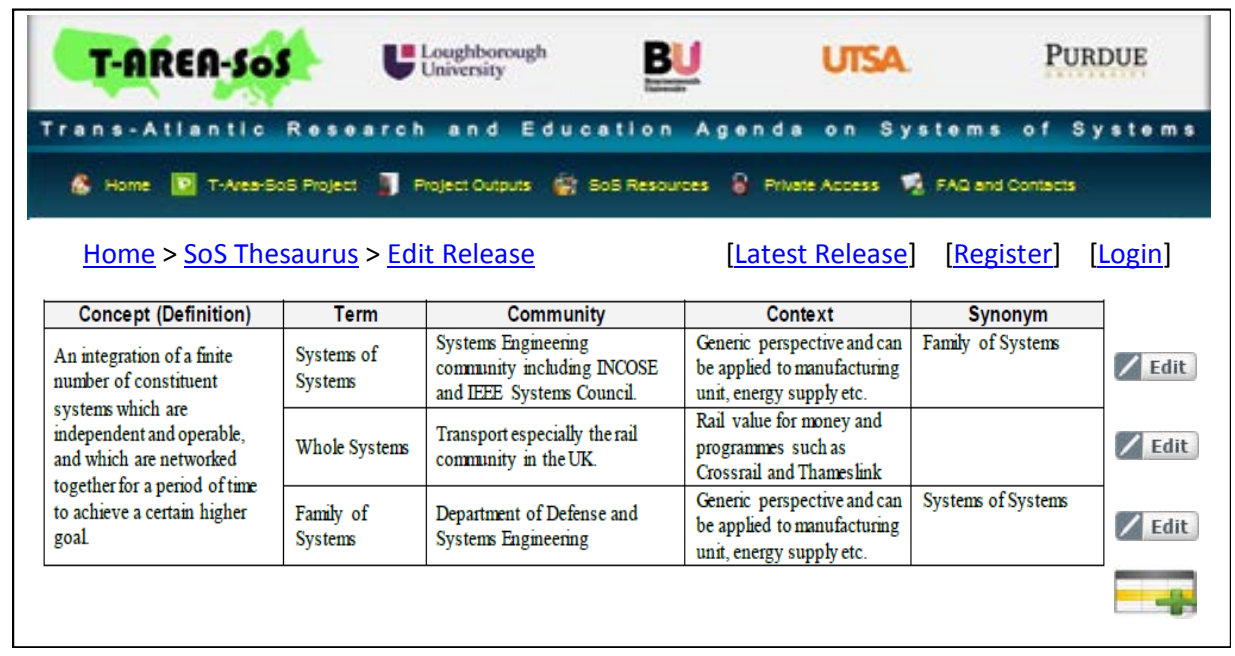

Figure 7: An example web-based thesaurus template

The thesaurus statement format for term and concept multiplicity and also the column heading of Table 1 and Table 2 are used to derive the templates for populating the 
thesaurus system. Consequently, four types of high-level access groups needs to be created; Viewers, Contributors, Domain Moderators and Principle Moderators. These are more centred on access privileges and moderation of the content. For example, viewers include guests (no login required) and those experts who are not allowed to contribute anything but just read the content. Contributors consist of all the experts who are allowed to add content to any section of the thesaurus. Any contribution must be approved by the relevant moderator (i.e. respective domain moderator) before being accepted to the thesaurus system. Principal Moderators consists of those experts who are relatively experienced in SoS and/or have multi-domain expertise. They have the highest weighing in terms of decision making within the thesaurus system. They can approve, modify, delete, and add any content within the thesaurus sections regardless of the domains sections.

This web based thesaurus and the taxonomy can support the meta-management of SoS and provide inputs into populating Maier's criteria (Maier 1998). There are concepts which can be mapped onto Maier's criteria to better understand the nature of modification required e.g. evolvement of Enterprise Architectures over time, and management of emergent behaviour through the architecture. This is just one example which relates to the different perceptions of the Enterprise Architecture and hence such developments require further work. The approach being taken can also be turned into a $\mathrm{n}: \mathrm{n}$ mapping of diverse terms used by diverse communities.

\subsection{Overall Contributions}

Discussions with members of the expert community at T-AREA-SoS workshops have indicated that the thesaurus has the potential to become an important resource for the SoS community. Firstly, it will underpin the SoS research agenda published within the European Community (T-AREA-SoS, 2013b) and should also provide the same underpinning for the domain SoS roadmaps that are being generated by the ROAD2SoS (2013) project. Secondly, it should form a useful resource for activities within Horizon $2020^{1}$, by helping to provide definitive terms for proposers and researchers, thus adding to the clarity of SoS-related outputs. Thirdly, together with resources from elsewhere in the emerging SoS discipline, it will support the development of theoretical foundations in SoS.

\section{Acknowledgements}

This work was supported by the European Commission, Grant Number: 287593.

\section{References}

ANSI. (2005) "Guidelines for the construction, format, and management of monolingual controlled vocabularies”, ANSI/NISO Z39.19.

Azarnoosh, H. et al. (2006) “Towards optimization of a real-world robotic-sensor system of systems”, Proceedings of World Automation Congress (WAC), Budapest, Hungary.

\footnotetext{
${ }^{1}$ Horizon 2020 - A new EU programme for research and innovation; €80 billion budget running from 2014 to 2020 .
} 
Barot, V. et al. (2012) “The SoSE Thesaurus Approach". Available from: https://www.tareasos.eu/results.php?user=anon (Accessed August 2012)

Barot, V. et al. (2013a) "Design of a Web-based Thesaurus for Systems of Systems Engineering”, $8^{\text {th }}$ International Conference on System of Systems Engineering (SoSE), Maui, Hawaii.

Barot, V. et al. (2013B) "State of the Art - V3.0", Available from: https://www.tareasos.eu/results.php?user=anon (Accessed August 2013)

COMPASS. (2012) http://www.compass-research.eu/. (Accessed 21 January 2012).

Catapano, T. et al. (2011) "Recommendations for the Use of knowledge organisation systems by GBIF”, Global Biodiversity Information Facility, Copenhagen, Denmark.

Dahmann, J. and K. Baldwin. (2008) "Understanding the Current State of US Defense Systems of Systems and the Implications for Systems Engineering." IEEE Systems Conference, 7-10 April, Montreal, Canada.

DANSE. (2012) http://www.danse-ip.eu/home/. (Accessed 21 January 2012).

Dickerson, C. E. (2008) “Towards a Logical and Scientific Foundation for System Concepts, Principles, and Terminology”, Proceedings of the Third IEEE International Conference on System of Systems Engineering, Montreal, California, USA.

Dickerson, C. E., and Mavris D. N. (2009) "Architecture and Principles of Systems Engineering”, (Complex and Enterprise Systems Engineering), Auerbach Publications, New York.

Dogan, H. et al (2013) "Formalisation and Mapping of Technologies for Systems of Systems Engineering Thesaurus”, $8^{\text {th }}$ International Conference on System of Systems Engineering (SoSE), Maui, Hawaii.

Duan, J. et al. (2009) "Ontology-based modelling of structural knowledge for modular mechanical products”, IEEE International Conference on Intelligent Computing and Intelligent Systems, Shanghai, China.

Elphick, J. (2011) "Rail Value for Money Study - Whole System Programme Management”, DfT and the ORR, Contract number RVFM 10004, Issue 1.4.

Gennari, J. et al. (2003) “The evolution of Protégé: an environment for knowledge-based systems development”, International Journal of Human-computer studies Vol. 58, No. 1.

Henrie, M., and Delaney, E. E. (2005) "Towards a common system of systems vocabulary”, IEEE International Conference on Systems, Man and Cybernetics, 10-12 Oct. 2005.

Henshaw, M. et al. (2012a) "Gap Analysis, Available from: https://www.tareasos.eu/results.php?user=anon. (Accessed August 2013). 
Barot et al.

Hotho, A. et al. (2006) "BibSonomy: A social bookmark and publication sharing system”, In Proceedings of the Conceptual Structures Tool Interoperability Workshop at the 14th International Conference on Conceptual Structures, Aalborg, Denmark.

Hughes, J. S. et al. (2009) "Ontology-based information model development for science information reuse and integration”, IEEE International Conference on Information Reuse and Integration, Nevada, USA.

Isaac, A. et al. (2009) “SKOS Simple Knowledge Organization System Primer”, W3C Working Group Note, World Wide Web Consortium.

ISO. (2011) "ISO 25964-1:2011 Information and documentation -- Thesauri and interoperability with other vocabularies -- Part 1: Thesauri for information retrieval”, Available from: http://www.iso.org/iso/iso_catalogue/catalogue_tc/catalogue_detail.htm?csnumber=5365 7. (Accessed 29 August 2013).

Jamshidi, M. (2009) "Systems of Systems Engineering - Innovations for the 21st Century”, John Wiley \& Sons, Hoboken, NJ.

Jupp, S. (2007) “Document navigation: ontologies or knowledge organisation systems”, In Proceedings of the Seventh International Workshop on Network Tools and Applications in Biology (NETTAB 2007), Pisa.

Keating, C.B. (2005) "Research foundations for system of systems engineering," IEEE International Conference on Systems, Man and Cybernetics, pp.2720-2725, 10-12 Oct. 2005.

Keating, C.B., and Katina, P.F. (2011) "Systems of systems engineering: prospects and challenges for the emerging field”, International Journal of System of Systems Engineering, Vol. 2, No 2/3, pp. 234-256

Keating, C.B., and Katina, P.F. (2012) "Prevalence of pathologies in systems of systems”, International Journal of System of Systems Engineering, Vol. 3, No. 3, pp. 243-267

Liu. X, et al. (2010) “Ontology based knowledge modelling and reuse approach in product design”, IEEE International Conference on Information Reuse and Integration, Nevada, USA.

Maier, M.W. (1998) “Architecting Principles for Systems-of-Systems”, Systems Engineering, Vol. 1, No. 4, pp. 267-284.

Neaga, E.I., M.J.d. Henshaw, and Y. Yue. (2009) "The influence of the concept of capability-based management on the development of the systems engineering discipline." Proc. 7th Annual Conf. Systems Engineering Research, 20th - 23rd April, Loughborough University, UK.

Newman, W. M. and Lamming, M. G. (1995) “Interactive System Design”, AddisonWesley, Wokingham, p. 468, 1995. 
Noy, N. et al. (2006) "A framework for ontology evolution in collaborative environments”, In The Semantic Web-ISWC 2006, Springer Berlin Heidelberg.

ROAD2SOS. (2013) "Development of strategic research and engineering roadmaps in Systems of Systems Engineering and related case studies", Available from: http://road2sos-project.eu/. (Accessed 05 September 2013).

Ross, J. et al. (2006) "Enterprise Architecture As Strategy, Creating a foundation for business execution”, Harvard business school press, Massachusetts.

Schober, D. (2009) "Concurrent, Collaborative Ontology Building with Collaborative Protégé (CP)”, University Medical Center, Freiburg.

Soergel, D. et al. (2006) "Reengineering thesauri for new applications: the AGROVOC example", Journal of digital information, Vol. 4, No. 4.

T-AREA-SoS. (2013a) “The SoSE Thesaurus V3.0”, Work Package 4, Deliverable D4.1, Trans-Atlantic Research and Education Agenda on Systems of Systems (T-AREA-SoS), Available from: https://www.tareasos.eu/results.php?user=anon. (Accessed 04 September 2013).

T-AREA-SoS. (2013b) "The Systems of Systems Strategic Research Agenda”, Doc. No.: TAREA-PU-WP5-R-LU-26, Issue 2, Released 15th August. Available from: https://www.tareasos.eu/docs/pb/SRA_Issue2.pdf (Accessed 30 November 2013).

Tolk, A., Adams, K. M., and Keating, C. B. (2011). Towards Intelligence-Based Systems Engineering and System of Systems Engineering. In Intelligence-Based Systems Engineering (pp. 1-22). Springer Berlin Heidelberg.

Tudorache, T. et al. (2008) "Supporting collaborative ontology development in Protégé", In The Semantic Web-ISWC 2008, Springer Berlin Heidelberg.

SIT (2006). Report on System of Systems Engineering: Submitted to the Secretary of defense. Stevens Institute of Technology, Hoboken, N.J.

Valerdi, R., Ross, A. M., and Rhodes, D. H. (2007) "A framework for evolving system of systems engineering”, CrossTalk, Vol. 20, No.10, pp28-30.Wielinga. B. J. et al. (2001) "From thesaurus to ontology", Proceedings of the 1st International Conference on Knowledge Capture, Victoria, Canada. 